\title{
Current Challenges Associated with the Use of Human Induced Pluripotent Stem Cell-Derived Organoids in Regenerative Medicine
}

\author{
Hana Lee ${ }^{1,2}$, Mi-Young Son ${ }^{1,2}$ \\ ${ }^{1}$ Korea Research Institute of Bioscience and Biotechnology (KRIBB), Daejeon, Korea, \\ ${ }^{2}$ KRIBB School of Bioscience, Korea University of Science and Technology (UST), Daejeon, Korea
}

\begin{abstract}
Innovative advances in stem cell research have resulted in the development of organoids, which are widely used as in vitro models of human organ development and for disease. The long-term goals of scientists include the generation of high-quality organoids with properties like those of native organs, and to expand their use to a variety of applications such as drug discovery and organoid-based cell therapy. In particular, the combination of human induced pluripotent stem cell (iPSC)-derived organoids with the recently developed genome engineering, biotechnology serve as an attractive platform in precision medicine. This review briefly summarizes the generation of organoids derived mostly from iPSCs without ethical issues, and describes the applications and technological advances of organoids under their differentiation and culture conditions. We also discuss the approaches to improve the organoid models, and how organoids can recapitulate mature organ systems of the human body for regenerative medicine. Finally, the future perspectives and remaining challenges in the field have been discussed to provide a better understanding of the potential applications of organoids.
\end{abstract}

Keywords: Induced pluripotent stem cell, Organoid, Application, Regenerative medicine

\section{Introduction}

For several decades, developmental biologists have studied aspects that can control stem cell behavior, such as

\footnotetext{
Received: September 8, 2020, Revised: October 23, 2020, Accepted: October 29, 2020, Published online: February 28, 2021 Correspondence to Mi-Young Son

Korea Research Institute of Bioscience and Biotechnology (KRIBB), 125 Gwahak-ro, Yuseong-gu, Daejeon 34141, Korea KRIBB School of Bioscience, Korea University of Science and Technology (UST), 217 Gajeong-ro, Yuseong-gu, Daejeon 34113, Korea Tel: +82-42-860-4426, Fax: +82-42-860-4608

E-mail: myson@kribb.re.kr

(c) This is an open-access article distributed under the terms of the Creative Commons Attribution Non-Commercial License (http://creativecommons.org/ licenses/by-nc/4.0/), which permits unrestricted non-commercial use, distribution, and reproduction in any medium, provided the original work is properly cited.
}

Copyright (c) 2021 by the Korean Society for Stem Cell Research differentiation and self-renewal, along with certain tissue lineages. To understand human biology, researchers have attempted to create models of the human developmental stages in vitro using human pluripotent stem cells (hPSCs), including human embryonic stem cells (hESCs) and induced pluripotent stem cells (iPSCs), even though established animal models such as fruit flies and mice already exist. The concepts and insights gained from the model organism systems have resulted in a significant shift from the use of stem cell models to three-dimensional (3D) structural organoids with organ-like properties, which serve as an ideal platform for studying stem cell development, tissue regeneration, and diseases in humans (1-3). However, generating perfect organs in vitro has been challenging, and scientists are trying to optimize this process.

As one of the promising hPSCs for organ formation, disease modeling, and applications in vitro, hESCs are unfortunately ethically controversial and limited in supply 
(4). On the other hand, human iPSC-derived organoids have overcome the limitations associated with using human tissue samples, and they maintain the unique cell types found in the long-term environment in vivo. Advances in extracellular matrix (ECM) biology $(5,6)$ have made it possible to observe in vitro morphology in a 3D laminin-rich matrix (7). Using this culture method, various organ systems have been generated by growing human iPSCs on an ECM-based hydrogel (8). Since the publication of this strategy, representative methods for developing of intestinal organoids (9), optic-cups (10), liver buds (11), cerebral organoids (12), gastric organoids (13), lung organoids (14), nephron organoids (15), ductal organoids (16), inner ear organoids (17), cardiac organoids (18), skin organoids (19), blood vessel organoids (20), and models of other organs have been established (Fig. 1).

Organoids have been acknowledged as an important platform for drug screening (21) and have the potential to be used for studying the effect of long-term alternative therapies in regenerative medicine (22). Additionally, organoid technology can be used for numerous purposes by coupling it with the following: genome editing with clustered regularly interspaced short palindromic repeats (CRISPR-Cas9) tools to obtain important insights into genetic disorders (23); co-culturing with pathogens for studying infectious diseases (24); and cancer modeling to understand cancer pathogenesis, development, and progression $(25,26)$. Principally, organoids serve as exploration tools

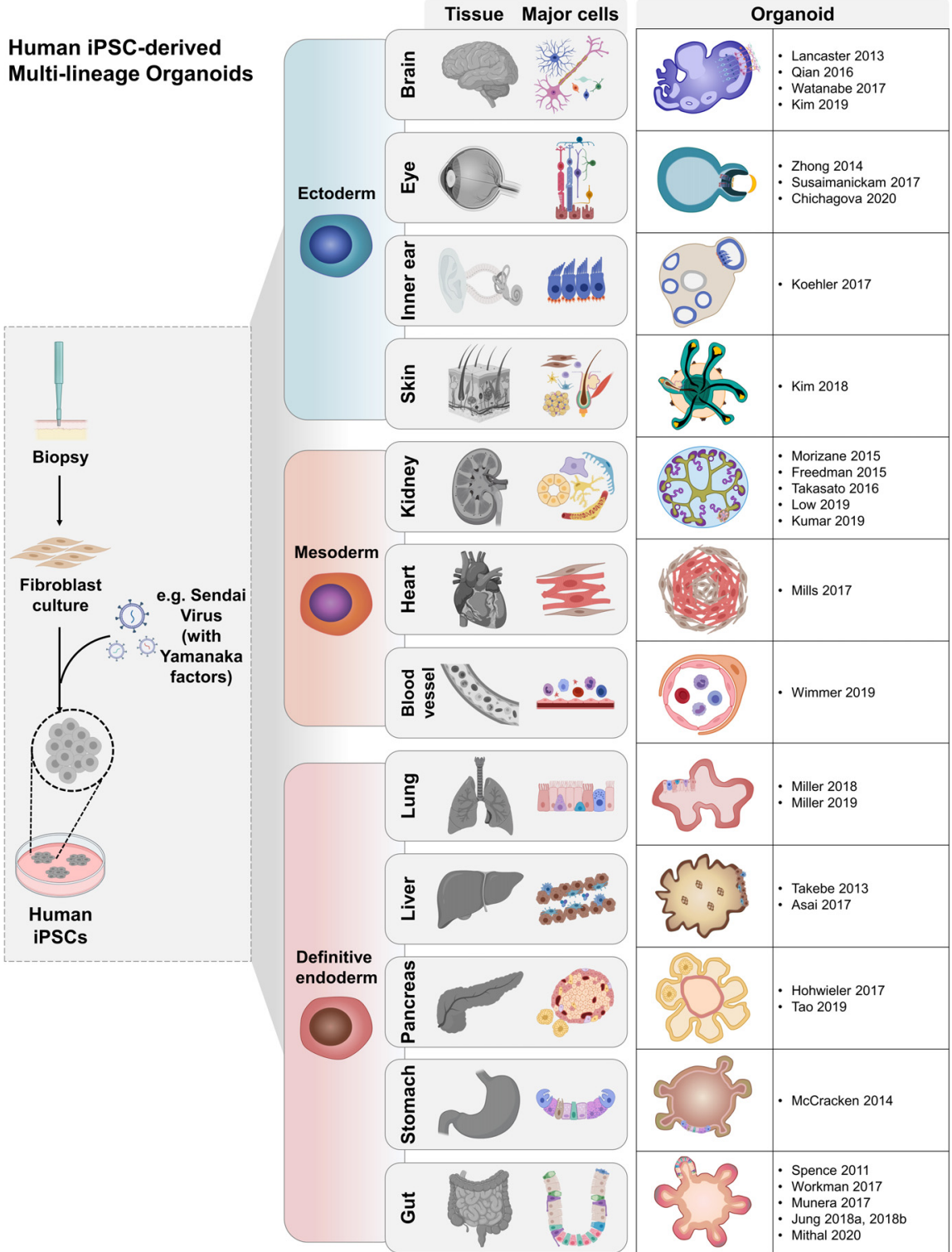

Fig. 1. Summary of the generation of iPSC-derived multilineage organoids. The generation of human iPSCs is depicted, and several organoid systems are listed along with their representative published protocols for generation. This figure was created using BioRender (https://biorender.com)). 
for understanding the processes underlying human development and diseases (13). However, despite the advances made, most of the human iPSC-derived organoids remain immature in cultures owing to the absence of important features found in adult tissues (27). Therefore, robust in vitro maturation methods that provide the required cellular and environmental constituents for producing functional and mature organoids are needed.

This review will explain the recent efforts at increasing the complexity of organoids and describe the current potential of using mature organoids in applications as diverse as bioengineering, disease modeling, drug discovery and regenerative medicine. We discuss the approaches to build the next-generation organoid, platform and highlight the challenges that need to be addressed for the organoid technology to reach its full potential in the field of regenerative medicine (28).

\section{Generation of Organoids}

Organoids are generated by leveraging the self-organizing and self-patterning properties of homogeneous cell populations (3). They are ex vivo "mini-organs" that contain fully differentiated cell types in the same spatial organization, as in the native organ. For the successful production of organoids, factors such as organ/tissue-specific cell types, proper culture conditions, signaling pathways responsible for regulating differentiation, and ECM (that influences the final properties of the organoids) must be considered.

\section{Initial stem cell types}

Adult stem cells (ASCs) $(24,29)$ and tissue-specific stem cells derived from hPSCs $(9,10,12,13)$ differ in their developmental potential, and thus follow their respective differentiation pathways in vitro. Therefore, depending on the purpose for which organoids are used, such as cell therapy, drug screening, or in studies of the basis of organ formation, the starting cell population is important (30). Additional areas that require further study include cell interactions during development, tissue biology, and translational medicine $(1,2)$. ASC-derived organoids are useful for research on the epithelial lining of the small intestine (29), large intestine (31) or stomach (32) which undergoes rapid regeneration, because these organoids exhibit characteristic intestinal epithelial regeneration and homeostasis even when cultured in vitro. However, there are practical limitations associated with obtaining enough ASCs. In contrast, iPSC-derived organoids have been generated by modulating various differentiation pathways in- volved in organ and tissue development, therefore iPSCs are usually used in studies that involve the recapitulation of processes associated with organ/tissue development in vitro. However, there have been hurdles in obtaining mature, "adult-like" cell types in hPSC-derived organoids (9). Additionally, co-culture of organoids with other cell types is required such as immune cells, nerve cells, and endothelial cells to improve the functional maturity and complexity of organoids $(11,33)$.

Signaling pathways involved in organoid differentiation

Most organoids are derived from a population of starting cells exposed to a particular morphogen at a defined point of time, resulting in the activation of the desired developmental signaling pathway. Notably, iPSC-derived organoids require exposure to specific growth factors at a precise time for differentiation into the target organs. Each organ is derived from three germ layers formed during embryonic development that undergo particular differentiation pathways. Diverse organs are formed from the same germ layer depending on the inductive signal. Precisely using these pathways to form organoids, along with the various combinations and concentrations of factors, and timing can cause different outcomes. Typically with intestinal organoids, the hindgut is formed from the posterior endoderm in response to induction by fibroblast growth factor (FGF)/Wnt (9). Gastric organoids induce foregut formation by inhibiting bone morphogenetic protein (BMP) signaling and generate the posterior foregut via retinoic acid signaling (13). Subsequently, the epidermal growth factor promotes the development of antral gastric organoids. Organoids can differentiate into fundic gastric organoids in response to continuous exposure to these conditions-activation of Wnt signaling; mitogen-activated protein kinase inhibition; BMP activation (34). Human colonic organoids (hCOs) can be produced by regulating BMP signaling after the formation of hindgut spheroids (35). iPSC-derived retinal organoids can be driven to differentiate into retinal tissue in vitro by modulating signaling pathways involving BMP4 and insulin-like growth factor 1 (36). FGF and sonic hedgehog proteins are required to promote the formation of lung organoids (14).

\section{ECM for 3D culture}

Currently, organoids are cultured using an ECM to build 3D culture environments. In many reports, the ECM from Engelbreth-Holm-Swarm murine sarcoma, Matrigel, has been mainly used for culturing cells $(11,17)$. Matrigel has been widely used in epithelial cell culture, but batchto-batch variability impedes reproducible in vitro studies, 
and its use in regenerative medicine is limited due to mouse tumor cell origins $(5,7)$. Therefore, strategies for 3D cultures that use synthetic hydrogels (37) and Type I Collagen gel (38) as alternatives have been reported. Moreover, tissue-specific ECMs were produced using extracellular matrix hydrogels derived from decellularized tissues, increasing the possibility of using organoids clinically (39). In contrast, 3D suspension cultures without solid scaffolds are used to culture renal (40), retinal (41), and cerebral organoids (42). The generation and characterization of cerebral (43), lung (44), and renal organoids (45) using an air-liquid interface method has been demonstrated.

\section{Development of iPSC-Derived Organoids}

Since 2010, numerous papers have described the generation of various iPSC-derived organoids that represent human tissues. These organoids can be divided into ectoderm, mesoderm, and endoderm according to the lineage-specific differentiation process to describe organoid formation. Brain, eye, inner ear, and skin organoid represent the ectoderm. The Lancaster group first developed the iPSC-derived cerebral organoid culture system, which has shown it can reproduce brain development (12). Models in which cerebral organoids containing neurons and glial cell types, including oligodendrocytes, have been created offer new opportunities to examine processes associated with early neuronal development and diseases (46-48). Even more, to predict the central nervous system permeability of drug compounds, a human choroidal plexus organoid with cerebrospinal fluid secretion was established and could be used in brain homeostasis studies (49). Similarly, retinal and corneal organoids have been generated that contain photoreceptor cells that respond to light stimulus; positive results have been reported following their use in cell therapy $(10,36,50)$. Ear organoids that contain sensory neurons and cochlear hair cells have recently been developed (17). Further, skin organoids that simulate the complex structure of human skin have been created (19). In mesoderm, one of the three germ layers, kidney, heart and recently blood vessels were developed. Renal organoids containing nephrons have been established which have recently been vascularized using ECM and suspension culture methods $(15,23,40,45,51)$. Blood vessel organoids, including epithelial cells and pericytes have been generated; the organoids exhibit self-assembly and vascular tree formation when implanted into mice (20). Importantly, cardiac organoids were developed by forced fusion via a biotechnology approach, and are being actively used in drug screening (18). In endoderm, in- testinal organoids were produced and developed in the early stages of organoid advancement (9). Progress has been made in developing mature human intestinal organoids (hIOs) and hCOs by employing various technologies $(33,35,52-54)$. Pancreatic organoids can secrete insulin and are evolving as an important model for the treatment of diabetes $(16,55)$. As reported, mesenchymal stem cells and umbilical vein endothelial cells are used to establish liver organoids, and albumin is produced from vascularized liver organoids are used in drug metabolism studies (11, 56). Lung organoids that constitute the basic bronchiole-like structure and alveoli have been developed (14, 57). Additionally, gastric organoids containing antral or fundic organoids, which differ in the structural location and function of the stomach, have been generated (13). Taken together, organoids of various tissues have been produced, and their number is growing rapidly (Fig. 1). Furthermore, novel multi-organoid systems (boundary-organoid, hepato-biliary-pancreatic) have been reported (58), and mesenchyme-free organoids generated using iPSC-derived hIOs have also been developed (54).

\section{Enhancement of the Organoid Maturity}

\section{Co-culture of various cells}

By stimulating cells with human developmental signals, it is possible to generate a variety of cell types present in vivo, such as neurons, vascular cells, and cells of the immune system (9). Recent studies have shown that hIOs are altered due to the enteric nervous system (ENS) when co-cultured with vagal neural crest cells (52). The co-cultured hIOs exhibited ENS integration effects regarding epithelial development; they also increased intestinal stem cell and transit-amplifying cell counts, and reduced the number of the differentiated absorptive and secretory intestinal cell types. This suggests that ENS could influence the differentiation trajectory of the hIOs. Furthermore, hIOs co-cultured with ENS may experience contractions like the peristaltic motion of the small intestine after implantation under the kidney capsule in vivo. It has been reported that intestinal cell-specific marker expression and functionality have improved in co-culture conditions with stimulated Jurkat cells or in response to treatment with interleukin-2 (IL-2), a major cytokine secreted by $\mathrm{T}$ lymphocytes (33). IL-2 was also found to maintain the hIO maturation effect when transplanted under renal capsules. Recently, the hIO maturation factor, IL-2, was reported to exhibit therapeutic effects on dextran sulfate sodium-induced ulcerative colitis (59). Co-culturing with endothelial cells and mesenchymal stem cells was attempted to im- 
prove the functions of human iPSC-derived hepatocytes in liver organoid models $(11,56)$. Mature organoids can be generated by introducing various cell types, such as nerve cells, immune cells, endothelial cells, and mesenchyme, i.e., cells surrounding the organ in vivo, besides improving the functional maturity and complexity of organoids (Fig. 2). In addition to using co-culture with organoids and other cell types to establish multilineage assembloids, it is also possible to create mutiregion assembloids model by fusing region-specific organoids of the same organ and controlling polarity or signal. This approach can explain fundamental questions about the actual organ formation process and disease mechanisms (60).

\section{In vivo transplantation into mammalian hosts}

In many studies, organoids have been transplanted into immunodeficient mice to enable maturation in vivo (Fig. 2). There are two approaches to organoid implantation; these include ectopic and orthotopic transplantation. Ectopic transplantations have been performed in the kid- ney capsule $(35,61)$, epididymal fat pad (57), and intestinal mesentery (62), which are highly vascularized sites that have access to nutrients in vivo. A hIO has shown significant maturation after transplantation under the kidney capsule for several weeks (61). The transplanted hIO generated a crypt-villus structure similar to that in adult tissues, and the mesenchymal lineage cells were differentiated to form smooth muscle layers. With orthotopic transplantation, the microenvironment of the native tissue and the therapeutic potential can be studied. For example, an implanted cerebral organoid was maintained for the long term ( $\sim 8$ months) after in vivo transplantation by intracerebral implantation, following which extensive axonal growth was observed (63). In addition, it has been confirmed that apoptosis decreases in the graft as vascularization takes place (64). Neuronal activities have been also recorded owing to the connection between the graft and the host. Collectively, the transplantation approaches could produce mature organoids and provide critical in vivo environments that influence the enhanced organoids.

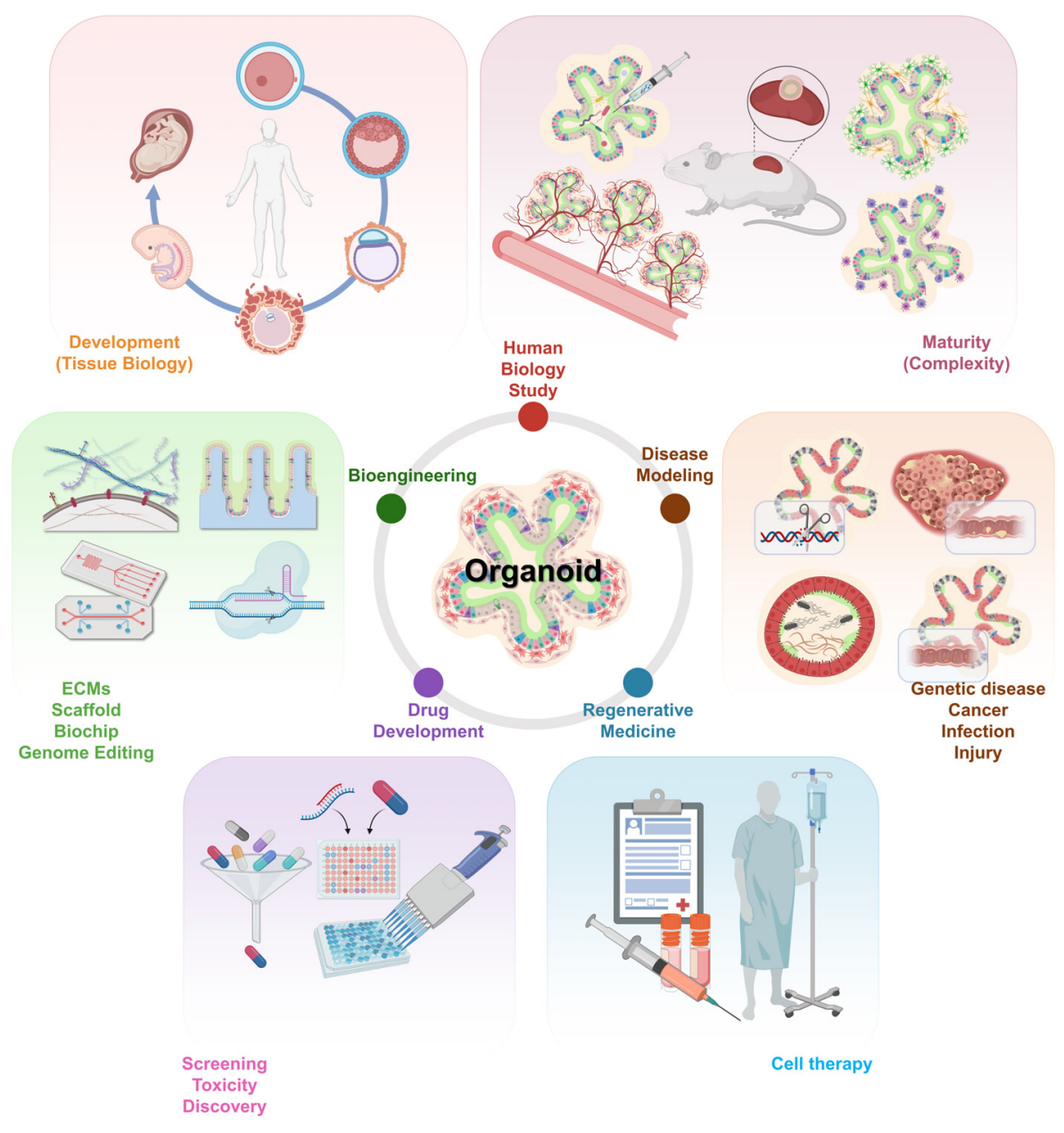

Fig. 2. The various applications of organoids. The scope of organoids in respective applications such as areas of human biology studies, disease modeling, regenerative medicine, drug development, and bioengineering has been illustrated. This figure was created using BioRender (https://biorender.com/). 
Although additional efforts are required to define the essential factors for further maturity, this approach made it possible to identify their potential in translational medicine.

\section{Organoid Applications}

Organoids have great potential for drug development and cell-based therapies, which are further combined with various applications, such as genome editing tools and organs-on-a-chip technologies. Moreover, new applications allow creating advanced organoids, which could have tremendous potential in translational and regenerative medicine.

\section{In vitro model for developmental study, disease modeling and testing}

In principle, the generation of iPSC-derived organoids needs to strictly mimic human organ development. Therefore, the process should be required precise spatiotemporal signals and correct concentrations essential for cell differentiation and tissue assembly (14, 35, 57). Organoids as 3D models have contributed to an in-depth understanding of human tissue/organ biology; this approach is more realistic than two-dimensional (2D) cultures and mammalian models (65). Moreover, organoids have provided an easily accessible system for identifying organ formation and have opened new avenues for studying human developmental biology (Fig. 2).

Compared to the conventional 2D model, the organoid systems can better simulate histopathological characteristics by assembling various cells. In addition, genetic disorders can be recapitulated using genome editing technology, and in the case of infectious diseases, organoids can be directly co-cultured with pathogens, providing models for disease mechanisms and pathophysiology. Based on these advantages of organoid systems, certain diseases have been studied, such as genetic disorders $(12,21)$, hostpathogen diseases $(13,24)$, and cancers $(25,26)$. Organoids generated from patient-derived iPSCs should clearly recapitulate human pathophysiology to better predict the efficacy and toxicity of drugs at a tissue/organ level by reflecting unique clinical responses to drugs in individual patients. Disease-specific biobanks can be used as a source of samples to test powerful alternative tools for drug screening and precision medicine approaches (66) (Fig. 2). In particular, organoids have been used in a system to test drugs to treat of Zika virus infection (46), and to develop personalized medicine for cystic fibrosis (21) and colorectal cancer (67).

\section{Improvement of organoid systems via bioengineering approaches}

Human iPSC-derived organoids are generated by simulating a human developmental process, but their structure differs from that of real organs. In addition, since it is difficult to deliver growth factors that induce the in vitro maturation into 3D structured organoids, except for in vivo transplantation, there are challenges in the continuous culture process of expandable and organ-mimicking organoids. Therefore, to address these limitations, novel biotechnology approaches, including genome engineering, organ-on-a-chip platforms, and ECM-based scaffolds, have been proposed $(37,55,68)$ (Fig. 2). A fluorescent reporter iPSC was created using CRISPR-Cas9 to expand the utilization of organoids, and the fluorescence of specific cell markers was observed during differentiation (53). Furthermore, LGR5-CreER knock-in colon organoids were generated for lineage tracing of $\mathrm{LGR}^{+}$intestinal stem cells (ISCs), and were transplanted into immunocompromised mice to observe the differences in stem cell cycling between species (28).

Organ-like bioengineered scaffolds are required for the cellular differentiation, organization, and activity, and they can also enhance the continuous culture process of organoids, to simulate the size and shape of actual organs by providing their physiological environment. For example, ISC cultures have maintained the shape of native small intestine with a crypt-villus structure when grown on a scaffold $(69,70)$. Besides, several studies have reported the use of chemically defined hydrogels (37) and collagen I (38) instead of Matrigel, to improve the growth of organoids and demonstrate clinical use. Applying hydrogels has led to developing photodegradable systems, whereby poly (ethylene glycol) hydrogels can also encapsulate embryonic stem cell-derived motor neurons and use infrared radiation for three-dimensional control. For physical micropatterning on the 3D tissue engineering scaffold, the structure within the hydrogel can be created using pulsed lasers and precisely controlled to enable the development of 3D cultured neural networks as well $(71,72)$. Alternatively, 3D bioprinting approaches that uniformly assemble cells in structures similar to those of adult organs, may decrease the variability of the organoid phenotypes and may be highly reproducible (73). The generation of organoids can be improved by growing microtubules on chips that mimic the scaffold and blood vessels, reproducing the required gradient of signal molecules (74). Organon-a-chip manufactured for organ-specific cell types can simulate a circulatory system with a microfluidic channel and has high reproducibility as an automated system. 
Organ-on-a-chip based on microfluidic technology allows cells to adapt to the culture environment of the chip system in which the medium is circulated within hollow microchannels (75). These devices can culture and maintain various types of cells simultaneously and predict drug response and toxicity at the organ- or body-levels, even as a multi-organ-on-a-chip. A multi-organ-on-a-chip, also known as a human-on-a-chip, contains various cell lines, including liver, lung, kidney, and adipose tissues, and a multi-channel 3D microfluidic system (76). Furthermore, an organ-on-a-chip is suitable for high-throughput systems including the drug or toxin screening, growth factor and/or signal identification, and may additionally study organ-organ and organ-vessel interaction (77).

\section{Host-microbial communications in organoid culture}

The human intestinal mucosal barrier and immune system definitively develop during late gestation and infancy periods, which are associated with the first exposure of commensal and pathogenic microorganisms in vivo (78). The interactions between organoids with commensal and pathogenic microbes and viruses play important roles in the physiology and function of the human body. Intestinal ecology affects important features such as digestion (79), metabolism (80), immune function (81) and brain development (82) through microbial colonization in early childhood. Therefore, introducing microbes into hIOs is necessary to understand colonization of various microorganisms in the human gut and their impact on early intestinal development. Especially gastrointestinal organoids which have niche components such as mucus layers will provide new insights into gastroenterological health and disease mechanisms. Several microbes have been microinjected into the lumen of closed hIOs to mimic intestinal host-microbial communications $(83,84)$ (Fig. 2). It was possible to observe the structural and functional changes in hIOs due to microbial colonization and confirm the interaction with microorganisms. Further research will broaden our understanding of the interactions of balanced microbiota with organs during human development (85), and to demonstrate the mechanisms of pathogenic microbial infection (86).

\section{Potential applications of organoids in cell therapy}

Organoids are an important component of cell therapy in regenerative medicine, and the implantation of organoids in animal models has been demonstrated with various approaches. For example, hIOs were transplanted into colonic injuries in mice, following which the colonic mucosal damage was regenerated after 4 weeks (28). In addi- tion, human iPSC-derived liver (11), kidney (87), and lung bud tips (14) were transplanted into each of the chemically induced damaged organs. An optic-cup was also transplanted in a mouse model with retinal degeneration to induce the photoreceptors and restore the synaptic connection to recover function (88). Human iPSC-derived brain organoids have been successfully implanted into the brains of adult mice, increasing the production of mature neuronal cells and the formation of synapses with host neurons (63). Overall, using orthotopic transplantation, it is possible to study the environment during the engraftment of organoids in vivo and confirm the application prospects of organoids in cell therapy (Fig. 2).

\section{Future Directions for Organoids in Regenerative Medicine}

Several studies have demonstrated rapid progress in organoid application, suggesting that organoids are a promising source for disease modeling, tissue engineering, and cell-based therapy in regenerative medicine. The production of mature organoids combined with challengeable applications can aid in the clinical treatment of tissues. Despite the aforementioned potential of organoids, numerous hurdles remain for achieving successful drug discovery and cell-based therapy. Ideally, protocols for differentiation of iPSC-derived organoids should be standardized for reproducibility and mass-production. Presently, iPSC-derived organoid systems are difficult to homogenize and lack scalability for high-throughput screens and large-scale cell therapy. Improving culture methods, including defined ECMs and multiscale micropatterning, may facilitate the production of more reproducible organoids. Additionally, for cell transplantation therapy, a defined ECM with excellent biocompatibility should be developed to replace Matrigel, and a scaffold that mimics real organ structure could be established. Conventional organoid differentiation protocols can generate a population of diverse cell types that occur spontaneously, but reducing their variability is a major challenge. Organoids with different characteristics are produced depending on the culture protocol, and specific mutations have been reported in patient-specific iPSC-derived organoids according to genetic background $(12,89)$. The introduction of gene editing technology can help generate new isogenic organoids that reduce background-related variability.

Based on the development methods of organoids mentioned in this review, organoids with stable scale-up capabilities and reproducibility should undergo three examinations before they are industrially produced as therapeutics. 


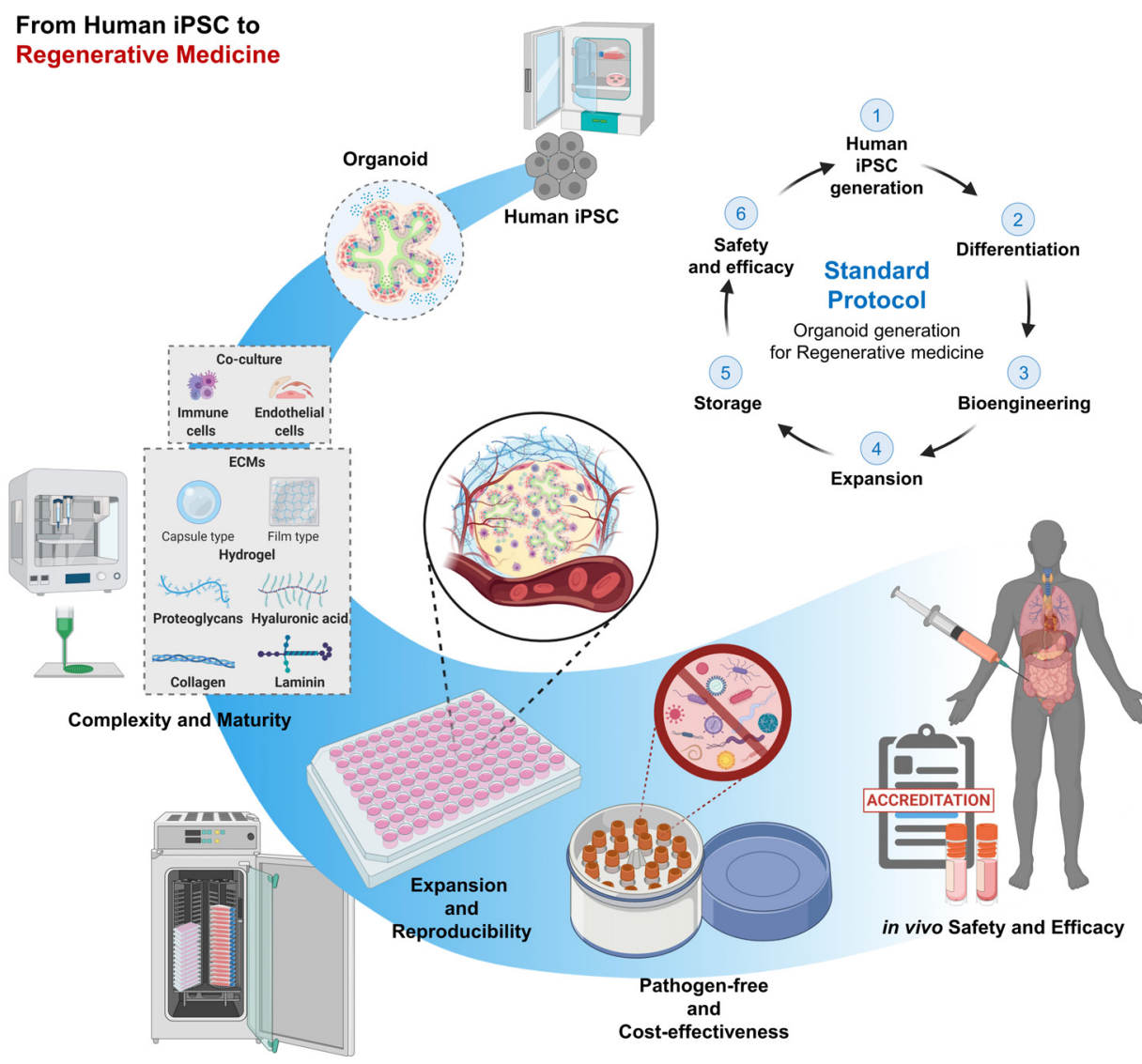

Fig. 3. Overview of the scale-up process for organoid applications covering iPSC generation to regenerative medicine. Developing a safe and cost-effective treatment based on a standardized protocol for organoid generation and scale-up of the culture process is depicted. This figure was created using BioRender (https://biorender.com/).
The first is to ensure a pathogen-free state that is directly linked to safety throughout the entire process from cell production to validation. Second, the use of advanced organoids in the industrial pharmaceutical pipeline requires the development of a storage or delivery method for organoids to optimize manufacturing costs. Finally, objective validation techniques for measuring the safety and efficacy of therapeutics in vivo should be established (90). These criteria must be met for organoids to work as drugs and some progress is already being made. Ultimately, multi-lineage organoid models can help reduce our reliance on animal models and provide new tools to treat human diseases. The various applications of the human iPSC-derived organoid systems presented here will play an important role in the future of regenerative medicine (Fig. 3).

\section{Conclusions}

Human iPSC-derived organoids are an accessible and physiologically relevant model system that can mimic the functions of human organs without ethical concerns regarding human embryos and interspecies differences.
Notably, organoids have tremendous potential in tissue biology research, disease modeling and alternative cell-based therapy. Moreover, in recent years, rapid progress has been made on the bioengineering aspects of ECM scaffolds, genome editing and organ-on-a-chip approaches to improve organoid functionality. Therefore, advanced organoid systems combined with various applications will undoubtedly expand the scope of regenerative medicine.

\section{Abbreviations}

2D: two-dimensional; 3D: three-dimensional; ASCs: adult stem cells; BMP: bone morphogenetic protein; CRISPR: clustered regularly interspaced short palindromic repeats; ECM: extracellular matrix; ENS: enteric nervous system; FGF: fibroblast growth factor; hCOs: human colonic organoids; hESCs: human embryonic stem cells; hIOs: human intestinal organoids; hPSCs: human pluripotent stem cells; iPSCs: induced pluripotent stem cells; ISCs: intestinal stem cells

\section{Acknowledgments}

This work was supported by a grant from the Technology 
Innovation Program (No. 20008777) and 3D-TissueChip Based Drug Discovery Platform Technology Development Program (No. 20009774 and No. 20009209) funded by the Ministry of Trade, Industry \& Energy (MOTIE, Korea), grant from the National Research Foundation of Korea (NRF) funded by the Ministry of Science, ICT and Future Planning (NRF-2018M3A9H3023077), Center for Agricultural Microorganism and Enzyme (Project No. PJ015049) of Rural Development Administration, and the KRIBB Research Initiative Program. The funders had no role in the study design, data collection or analysis, decision to publish, or preparation of the manuscript. Figures were created using the site BioRender.com.

\section{Potential Conflict of Interest}

The authors have no conflicting financial interest.

\section{References}

1. Clevers H. Modeling development and disease with organoids. Cell 2016;165:1586-1597

2. Lancaster MA, Knoblich JA. Organogenesis in a dish: modeling development and disease using organoid technologies. Science 2014;345:1247125

3. Sasai Y. Cytosystems dynamics in self-organization of tissue architecture. Nature 2013;493:318-326

4. Yu J, Vodyanik MA, Smuga-Otto K, Antosiewicz-Bourget J, Frane JL, Tian S, Nie J, Jonsdottir GA, Ruotti V, Stewart $\mathrm{R}$, Slukvin II, Thomson JA. Induced pluripotent stem cell lines derived from human somatic cells. Science 2007;318: 1917-1920

5. Orkin RW, Gehron P, McGoodwin EB, Martin GR, Valentine T, Swarm R. A murine tumor producing a matrix of basement membrane. J Exp Med 1977;145:204-220

6. Ehrmann RL, Gey GO. The growth of cells on a transparent gel of reconstituted rat-tail collagen. J Natl Cancer Inst 1956;16:1375-1403

7. Hughes CS, Postovit LM, Lajoie GA. Matrigel: a complex protein mixture required for optimal growth of cell culture. Proteomics 2010;10:1886-1890

8. Freytes DO, Martin J, Velankar SS, Lee AS, Badylak SF. Preparation and rheological characterization of a gel form of the porcine urinary bladder matrix. Biomaterials 2008; 29:1630-1637

9. Spence JR, Mayhew CN, Rankin SA, Kuhar MF, Vallance JE, Tolle K, Hoskins EE, Kalinichenko VV, Wells SI, Zorn AM, Shroyer NF, Wells JM. Directed differentiation of human pluripotent stem cells into intestinal tissue in vitro. Nature 2011;470:105-109

10. Zhong X, Gutierrez C, Xue T, Hampton C, Vergara MN, Cao LH, Peters A, Park TS, Zambidis ET, Meyer JS, Gamm DM, Yau KW, Canto-Soler MV. Generation of three-dimensional retinal tissue with functional photo- receptors from human iPSCs. Nat Commun 2014;5:4047

11. Takebe T, Sekine K, Enomura M, Koike H, Kimura M, Ogaeri T, Zhang RR, Ueno Y, Zheng YW, Koike N, Aoyama S, Adachi Y, Taniguchi H. Vascularized and functional human liver from an iPSC-derived organ bud transplant. Nature 2013;499:481-484

12. Lancaster MA, Renner M, Martin CA, Wenzel D, Bicknell LS, Hurles ME, Homfray T, Penninger JM, Jackson AP, Knoblich JA. Cerebral organoids model human brain development and microcephaly. Nature 2013;501:373-379

13. McCracken KW, Catá EM, Crawford CM, Sinagoga KL, Schumacher M, Rockich BE, Tsai YH, Mayhew CN, Spence JR, Zavros Y, Wells JM. Modelling human development and disease in pluripotent stem-cell-derived gastric organoids. Nature 2014;516:400-404

14. Miller AJ, Hill DR, Nagy MS, Aoki Y, Dye BR, Chin AM, Huang S, Zhu F, White ES, Lama V, Spence JR. In vitro induction and in vivo engraftment of lung bud tip progenitor cells derived from human pluripotent stem cells. Stem Cell Reports 2018;10:101-119

15. Morizane R, Lam AQ, Freedman BS, Kishi S, Valerius MT, Bonventre JV. Nephron organoids derived from human pluripotent stem cells model kidney development and injury. Nat Biotechnol 2015;33:1193-1200

16. Hohwieler M, Illing A, Hermann PC, Mayer T, Stockmann M, Perkhofer L, Eiseler T, Antony JS, Müller M, Renz S, Kuo CC, Lin Q, Sendler M, Breunig M, Kleiderman SM, Lechel A, Zenker M, Leichsenring M, Rosendahl J, Zenke M, Sainz B Jr, Mayerle J, Costa IG, Seufferlein T, Kormann M, Wagner M, Liebau S, Kleger A. Human pluripotent stem cell-derived acinar/ductal organoids generate human pancreas upon orthotopic transplantation and allow disease modelling. Gut 2017;66:473-486

17. Koehler KR, Nie J, Longworth-Mills E, Liu XP, Lee J, Holt JR, Hashino E. Generation of inner ear organoids containing functional hair cells from human pluripotent stem cells. Nat Biotechnol 2017;35:583-589

18. Mills RJ, Titmarsh DM, Koenig X, Parker BL, Ryall JG, Quaife-Ryan GA, Voges HK, Hodson MP, Ferguson C, Drowley L, Plowright AT, Needham EJ, Wang QD, Gregorevic P, Xin M, Thomas WG, Parton RG, Nielsen LK, Launikonis BS, James DE, Elliott DA, Porrello ER, Hudson JE. Functional screening in human cardiac organoids reveals a metabolic mechanism for cardiomyocyte cell cycle arrest. Proc Natl Acad Sci U S A 2017;114:E8372-E8381

19. Kim Y, Park N, Rim YA, Nam Y, Jung H, Lee K, Ju JH. Establishment of a complex skin structure via layered co-culture of keratinocytes and fibroblasts derived from induced pluripotent stem cells. Stem Cell Res Ther 2018;9:217

20. Wimmer RA, Leopoldi A, Aichinger M, Wick N, Hantusch B, Novatchkova $M$, Taubenschmid J, Hämmerle M, Esk C, Bagley JA, Lindenhofer D, Chen G, Boehm M, Agu CA, Yang F, Fu B, Zuber J, Knoblich JA, Kerjaschki D, Penninger JM. Human blood vessel organoids as a model of diabetic vasculopathy. Nature 2019;565:505-510

21. Dekkers JF, Wiegerinck CL, de Jonge HR, Bronsveld I, 
Janssens HM, de Winter-de Groot KM, Brandsma AM, de Jong NW, Bijvelds MJ, Scholte BJ, Nieuwenhuis EE, van den Brink S, Clevers H, van der Ent CK, Middendorp S, Beekman JM. A functional CFTR assay using primary cystic fibrosis intestinal organoids. Nat Med 2013;19:939-945

22. Yui S, Nakamura T, Sato T, Nemoto Y, Mizutani T, Zheng $\mathrm{X}$, Ichinose S, Nagaishi T, Okamoto R, Tsuchiya $\mathrm{K}$, Clevers $H$, Watanabe $M$. Functional engraftment of colon epithelium expanded in vitro from a single adult $\mathrm{Lgr}^{+}$stem cell. Nat Med 2012;18:618-623

23. Freedman BS, Brooks CR, Lam AQ, Fu H, Morizane R, Agrawal V, Saad AF, Li MK, Hughes MR, Werff RV, Peters DT, Lu J, Baccei A, Siedlecki AM, Valerius MT, Musunuru K, McNagny KM, Steinman TI, Zhou J, Lerou PH, Bonventre JV. Modelling kidney disease with CRISPR-mutant kidney organoids derived from human pluripotent epiblast spheroids. Nat Commun 2015;6:8715

24. Bartfeld S, Bayram T, van de Wetering $M$, Huch $M$, Begthel H, Kujala P, Vries R, Peters PJ, Clevers H. In vitro expansion of human gastric epithelial stem cells and their responses to bacterial infection. Gastroenterology 2015;148:126-136.e6

25. Drost J, Karthaus WR, Gao D, Driehuis E, Sawyers CL, Chen Y, Clevers H. Organoid culture systems for prostate epithelial and cancer tissue. Nat Protoc 2016;11:347-358

26. Boj SF, Hwang CI, Baker LA, Chio II, Engle DD, Corbo V, Jager $M$, Ponz-Sarvise $M$, Tiriac $H$, Spector MS, Gracanin A, Oni T, Yu KH, van Boxtel R, Huch M, Rivera KD, Wilson JP, Feigin ME, Öhlund D, Handly-Santana A, Ardito-Abraham CM, Ludwig M, Elyada E, Alagesan B, Biffi G, Yordanov GN, Delcuze B, Creighton B, Wright K, Park Y, Morsink FH, Molenaar IQ, Borel Rinkes IH, Cuppen E, Hao Y, Jin Y, Nijman IJ, Iacobuzio-Donahue C, Leach SD, Pappin DJ, Hammell M, Klimstra DS, Basturk O, Hruban RH, Offerhaus GJ, Vries RG, Clevers $\mathrm{H}$, Tuveson DA. Organoid models of human and mouse ductal pancreatic cancer. Cell 2015;160:324-338

27. Chinta MS, desJardins-Park HE, Wan DC, Longaker MT. "Tissues in a dish": a review of organoids in plastic surgery. Plast Reconstr Surg Glob Open 2020;8:e2787

28. Sugimoto S, Ohta Y, Fujii $M$, Matano M, Shimokawa M, Nanki K, Date S, Nishikori S, Nakazato Y, Nakamura T, Kanai T, Sato T. Reconstruction of the human colon epithelium in vivo. Cell Stem Cell 2018;22:171-176.e5

29. Sato T, Vries RG, Snippert HJ, van de Wetering M, Barker N, Stange DE, van Es JH, Abo A, Kujala P, Peters PJ, Clevers H. Single Lgr5 stem cells build crypt-villus structures in vitro without a mesenchymal niche. Nature 2009; 459:262-265

30. Harrison SE, Sozen B, Christodoulou N, Kyprianou C, Zernicka-Goetz M. Assembly of embryonic and extraembryonic stem cells to mimic embryogenesis in vitro. Science 2017;356:eaal1810

31. Sato T, Stange DE, Ferrante M, Vries RG, Van Es JH, Van den Brink S, Van Houdt WJ, Pronk A, Van Gorp J, Siersema PD, Clevers H. Long-term expansion of epithelial organoids from human colon, adenoma, adenocarcinoma, and Barrett's epithelium. Gastroenterology 2011;141:1762-1772

32. Barker $N$, Huch $M$, Kujala $P$, van de Wetering $M$, Snippert $\mathrm{HJ}$, van Es JH, Sato T, Stange DE, Begthel H, van den Born M, Danenberg E, van den Brink S, Korving J, Abo A, Peters PJ, Wright N, Poulsom R, Clevers H. Lgr5(+ve) stem cells drive self-renewal in the stomach and build long-lived gastric units in vitro. Cell Stem Cell 2010;6:25-36

33. Jung KB, Lee H, Son YS, Lee MO, Kim YD, Oh SJ, Kwon O, Cho S, Cho HS, Kim DS, Oh JH, Zilbauer M, Min JK, Jung CR, Kim J, Son MY. Interleukin-2 induces the in vitro maturation of human pluripotent stem cell-derived intestinal organoids. Nat Commun 2018;9:3039

34. McCracken KW, Aihara E, Martin B, Crawford CM, Broda T, Treguier J, Zhang X, Shannon JM, Montrose MH, Wells JM. Wnt/ $\beta$-catenin promotes gastric fundus specification in mice and humans. Nature 2017;541:182-187

35. Múnera JO, Sundaram N, Rankin SA, Hill D, Watson C, Mahe M, Vallance JE, Shroyer NF, Sinagoga KL, Zarzoso-Lacoste A, Hudson JR, Howell JC, Chatuvedi P, Spence JR, Shannon JM, Zorn AM, Helmrath MA, Wells JM. Differentiation of human pluripotent stem cells into colonic organoids via transient activation of BMP signaling. Cell Stem Cell 2017;21:51-64.e6

36. Chichagova V, Hilgen G, Ghareeb A, Georgiou M, Carter M, Sernagor E, Lako M, Armstrong L. Human iPSC differentiation to retinal organoids in response to IGF1 and BMP4 activation is line- and method-dependent. Stem Cells 2020;38:195-201

37. Cruz-Acuña R, Quirós M, Farkas AE, Dedhia PH, Huang S, Siuda D, García-Hernández V, Miller AJ, Spence JR, Nusrat A, García AJ. Synthetic hydrogels for human intestinal organoid generation and colonic wound repair. Nat Cell Biol 2017;19:1326-1335

38. Sachs N, Tsukamoto Y, Kujala P, Peters PJ, Clevers H. Intestinal epithelial organoids fuse to form self-organizing tubes in floating collagen gels. Development 2017;144:11071112

39. Giobbe GG, Crowley C, Luni C, Campinoti S, Khedr M, Kretzschmar K, De Santis MM, Zambaiti E, Michielin F, Meran L, Hu Q, van Son G, Urbani L, Manfredi A, Giomo M, Eaton S, Cacchiarelli D, Li VSW, Clevers H, Bonfanti P, Elvassore N, De Coppi P. Extracellular matrix hydrogel derived from decellularized tissues enables endodermal organoid culture. Nat Commun 2019;10:5658

40. Kumar SV, Er PX, Lawlor KT, Motazedian A, Scurr M, Ghobrial I, Combes AN, Zappia L, Oshlack A, Stanley EG, Little $\mathrm{MH}$. Kidney micro-organoids in suspension culture as a scalable source of human pluripotent stem cell-derived kidney cells. Development 2019;146:dev172361

41. DiStefano T, Chen HY, Panebianco C, Kaya KD, Brooks MJ, Gieser L, Morgan NY, Pohida T, Swaroop A. Accelerated and improved differentiation of retinal organoids from pluripotent stem cells in rotating-wall vessel bioreactors. Stem Cell Reports 2018;10:300-313

42. Muguruma K, Nishiyama A, Kawakami H, Hashimoto K, Sasai Y. Self-organization of polarized cerebellar tissue in 
3D culture of human pluripotent stem cells. Cell Rep 2015; 10:537-550

43. Giandomenico SL, Mierau SB, Gibbons GM, Wenger LMD, Masullo L, Sit T, Sutcliffe M, Boulanger J, Tripodi M, Derivery E, Paulsen O, Lakatos A, Lancaster MA. Cerebral organoids at the air-liquid interface generate diverse nerve tracts with functional output. Nat Neurosci 2019;22:669-679

44. Upadhyay S, Palmberg L. Air-liquid interface: relevant in vitro models for investigating air pollutant-induced pulmonary toxicity. Toxicol Sci 2018;164:21-30

45. Takasato M, Er PX, Chiu HS, Little MH. Generation of kidney organoids from human pluripotent stem cells. Nat Protoc 2016;11:1681-1692

46. Watanabe M, Buth JE, Vishlaghi N, de la Torre-Ubieta L, Taxidis J, Khakh BS, Coppola G, Pearson CA, Yamauchi K, Gong D, Dai X, Damoiseaux R, Aliyari R, Liebscher S, Schenke-Layland K, Caneda C, Huang EJ, Zhang Y, Cheng G, Geschwind DH, Golshani P, Sun R, Novitch BG. Self-organized cerebral organoids with human-specific features predict effective drugs to combat Zika virus infection. Cell Rep 2017;21:517-532

47. Qian X, Nguyen HN, Song MM, Hadiono C, Ogden SC, Hammack C, Yao B, Hamersky GR, Jacob F, Zhong C, Yoon KJ, Jeang W, Lin L, Li Y, Thakor J, Berg DA, Zhang C, Kang E, Chickering M, Nauen D, Ho CY, Wen Z, Christian KM, Shi PY, Maher BJ, Wu H, Jin P, Tang H, Song H, Ming GL. Brain-region-specific organoids using mini-bioreactors for modeling ZIKV exposure. Cell 2016; 165:1238-1254

48. Kim H, Xu R, Padmashri R, Dunaevsky A, Liu Y, Dreyfus $\mathrm{CF}$, Jiang P. Pluripotent stem cell-derived cerebral organoids reveal human oligodendrogenesis with dorsal and ventral origins. Stem Cell Reports 2019;12:890-905

49. Pellegrini L, Bonfio C, Chadwick J, Begum F, Skehel M, Lancaster MA. Human CNS barrier-forming organoids with cerebrospinal fluid production. Science 2020;369:eaaz5626

50. Susaimanickam PJ, Maddileti S, Pulimamidi VK, Boyinpally SR, Naik RR, Naik MN, Reddy GB, Sangwan VS, Mariappan I. Generating minicorneal organoids from human induced pluripotent stem cells. Development 2017;144:2338-2351

51. Low JH, Li P, Chew EGY, Zhou B, Suzuki K, Zhang T, Lian MM, Liu M, Aizawa E, Rodriguez Esteban C, Yong KSM, Chen Q, Campistol JM, Fang M, Khor CC, Foo JN, Izpisua Belmonte JC, Xia Y. Generation of human PSC-derived kidney organoids with patterned nephron segments and a de novo vascular network. Cell Stem Cell 2019;25: 373-387.e9

52. Workman MJ, Mahe MM, Trisno S, Poling HM, Watson CL, Sundaram N, Chang CF, Schiesser J, Aubert P, Stanley EG, Elefanty AG, Miyaoka Y, Mandegar MA, Conklin BR, Neunlist M, Brugmann SA, Helmrath MA, Wells JM. Engineered human pluripotent-stem-cell-derived intestinal tissues with a functional enteric nervous system. Nat Med 2017;23:49-59

53. Jung KB, Lee H, Son YS, Lee JH, Cho HS, Lee MO, Oh JH,
Lee J, Kim S, Jung CR, Kim J, Son MY. In vitro and in vivo imaging and tracking of intestinal organoids from human induced pluripotent stem cells. FASEB J 2018;32:111-122

54. Mithal A, Capilla A, Heinze D, Berical A, VillacortaMartin C, Vedaie M, Jacob A, Abo K, Szymaniak A, Peasley M, Stuffer A, Mahoney J, Kotton DN, Hawkins F, Mostoslavsky G. Generation of mesenchyme free intestinal organoids from human induced pluripotent stem cells. Nat Commun 2020;11:215

55. Tao T, Wang Y, Chen W, Li Z, Su W, Guo Y, Deng P, Qin J. Engineering human islet organoids from iPSCs using an organ-on-chip platform. Lab Chip 2019;19:948-958

56. Asai A, Aihara E, Watson C, Mourya R, Mizuochi T, Shivakumar P, Phelan K, Mayhew C, Helmrath M, Takebe T, Wells J, Bezerra JA. Paracrine signals regulate human liver organoid maturation from induced pluripotent stem cells. Development 2017;144:1056-1064

57. Miller AJ, Dye BR, Ferrer-Torres D, Hill DR, Overeem AW, Shea LD, Spence JR. Generation of lung organoids from human pluripotent stem cells in vitro. Nat Protoc 2019;14:518-540

58. Koike H, Iwasawa K, Ouchi R, Maezawa M, Giesbrecht K, Saiki N, Ferguson A, Kimura M, Thompson WL, Wells JM, Zorn AM, Takebe T. Modelling human hepato-biliary-pancreatic organogenesis from the foregut-midgut boundary. Nature 2019;574:112-116

59. Lee H, Son YS, Lee MO, Ryu JW, Park K, Kwon O, Jung KB, Kim K, Ryu TY, Baek A, Kim J, Jung CR, Ryu CM, Park YJ, Han TS, Kim DS, Cho HS, Son MY. Low-dose interleukin-2 alleviates dextran sodium sulfate-induced colitis in mice by recovering intestinal integrity and inhibiting AKT-dependent pathways. Theranostics 2020;10:5048-5063

60. Paşca SP. Assembling human brain organoids. Science 2019;363:126-127

61. Watson CL, Mahe MM, Múnera J, Howell JC, Sundaram N, Poling HM, Schweitzer JI, Vallance JE, Mayhew CN, Sun Y, Grabowski G, Finkbeiner SR, Spence JR, Shroyer NF, Wells JM, Helmrath MA. An in vivo model of human small intestine using pluripotent stem cells. Nat Med 2014; 20:1310-1314

62. Cortez AR, Poling HM, Brown NE, Singh A, Mahe MM, Helmrath MA. Transplantation of human intestinal organoids into the mouse mesentery: a more physiologic and anatomic engraftment site. Surgery 2018;164:643-650

63. Mansour AA, Gonçalves JT, Bloyd CW, Li H, Fernandes S, Quang D, Johnston S, Parylak SL, Jin X, Gage FH. An in vivo model of functional and vascularized human brain organoids. Nat Biotechnol 2018;36:432-441

64. Hill J, Cave J. Targeting the vasculature to improve neural progenitor transplant survival. Transl Neurosci 2015;6:162-167

65. Takebe T, Wells JM. Organoids by design. Science 2019; 364:956-959

66. Czerniecki SM, Cruz NM, Harder JL, Menon R, Annis J, Otto EA, Gulieva RE, Islas LV, Kim YK, Tran LM, Martins TJ, Pippin JW, Fu H, Kretzler M, Shankland SJ, Himmelfarb J, Moon RT, Paragas N, Freedman BS. High- 
throughput screening enhances kidney organoid differentiation from human pluripotent stem cells and enables automated multidimensional phenotyping. Cell Stem Cell 2018;22:929-940.e4

67. Crespo M, Vilar E, Tsai SY, Chang K, Amin S, Srinivasan $\mathrm{T}$, Zhang $\mathrm{T}$, Pipalia NH, Chen HJ, Witherspoon $M$, Gordillo M, Xiang JZ, Maxfield FR, Lipkin S, Evans T, Chen S. Colonic organoids derived from human induced pluripotent stem cells for modeling colorectal cancer and drug testing. Nat Med 2017;23:878-884

68. Tocchio A, Tamplenizza M, Martello F, Gerges I, Rossi E, Argentiere S, Rodighiero S, Zhao W, Milani P, Lenardi C. Versatile fabrication of vascularizable scaffolds for large tissue engineering in bioreactor. Biomaterials 2015;45:124-131

69. Wang Y, Gunasekara DB, Reed MI, DiSalvo M, Bultman SJ, Sims CE, Magness ST, Allbritton NL. A microengineered collagen scaffold for generating a polarized cryptvillus architecture of human small intestinal epithelium. Biomaterials 2017;128:44-55

70. Nikolaev M, Mitrofanova O, Broguiere N, Geraldo S, Dutta D, Tabata Y, Elci B, Brandenberg N, Kolotuev I, Gjorevski $\mathrm{N}$, Clevers H, Lutolf MP. Homeostatic mini-intestines through scaffold-guided organoid morphogenesis. Nature 2020;585:574-578

71. McKinnon DD, Brown TE, Kyburz KA, Kiyotake E, Anseth KS. Design and characterization of a synthetically accessible, photodegradable hydrogel for user-directed formation of neural networks. Biomacromolecules 2014;15:2808-2816

72. Sarig-Nadir O, Livnat N, Zajdman R, Shoham S, Seliktar D. Laser photoablation of guidance microchannels into hydrogels directs cell growth in three dimensions. Biophys J 2009;96:4743-4752

73. Zhu W, Qu X, Zhu J, Ma X, Patel S, Liu J, Wang P, Lai CS, Gou M, Xu Y, Zhang K, Chen S. Direct 3D bioprinting of prevascularized tissue constructs with complex microarchitecture. Biomaterials 2017;124:106-115

74. Demers CJ, Soundararajan P, Chennampally P, Cox GA, Briscoe J, Collins SD, Smith RL. Development-on-chip: in vitro neural tube patterning with a microfluidic device. Development 2016;143:1884-1892

75. Fabre KM, Livingston C, Tagle DA. Organs-on-chips (microphysiological systems): tools to expedite efficacy and toxicity testing in human tissue. Exp Biol Med (Maywood) 2014;239:1073-1077

76. Zhang C, Zhao Z, Abdul Rahim NA, van Noort D, Yu H. Towards a human-on-chip: culturing multiple cell types on a chip with compartmentalized microenvironments. Lab Chip 2009;9:3185-3192

77. Ronaldson-Bouchard K, Vunjak-Novakovic G. Organs-on-achip: a fast track for engineered human tissues in drug development. Cell Stem Cell 2018;22:310-324

78. Peterson LW, Artis D. Intestinal epithelial cells: regulators of barrier function and immune homeostasis. Nat Rev Immunol 2014;14:141-153

79. Erkosar B, Storelli G, Mitchell M, Bozonnet L, Bozonnet N, Leulier F. Pathogen virulence impedes mutualist-medi- ated enhancement of host juvenile growth via inhibition of protein digestion. Cell Host Microbe 2015;18:445-455

80. Cho I, Yamanishi S, Cox L, Methé BA, Zavadil J, Li K, Gao Z, Mahana D, Raju K, Teitler I, Li H, Alekseyenko $\mathrm{AV}$, Blaser MJ. Antibiotics in early life alter the murine colonic microbiome and adiposity. Nature 2012;488:621-626

81. Hviid A, Svanström H, Frisch M. Antibiotic use and inflammatory bowel diseases in childhood. Gut 2011;60:49-54

82. Diaz Heijtz R, Wang S, Anuar F, Qian Y, Björkholm B, Samuelsson A, Hibberd ML, Forssberg H, Pettersson S. Normal gut microbiota modulates brain development and behavior. Proc Natl Acad Sci U S A 2011;108:3047-3052

83. Leslie JL, Huang S, Opp JS, Nagy MS, Kobayashi M, Young VB, Spence JR. Persistence and toxin production by Clostridium difficile within human intestinal organoids result in disruption of epithelial paracellular barrier function. Infect Immun 2015;83:138-145

84. Son YS, Ki SJ, Thanavel R, Kim JJ, Lee MO, Kim J, Jung CR, Han TS, Cho HS, Ryu CM, Kim SH, Park DS, Son MY. Maturation of human intestinal organoids in vitro facilitates colonization by commensal lactobacilli by reinforcing the mucus layer. FASEB J 2020 [Epub ahead of print]

85. Vatanen T, Plichta DR, Somani J, Münch PC, Arthur TD, Hall AB, Rudolf S, Oakeley EJ, Ke X, Young RA, Haiser HJ, Kolde R, Yassour M, Luopajärvi K, Siljander H, Virtanen SM, Ilonen J, Uibo R, Tillmann V, Mokurov S, Dorshakova N, Porter JA, McHardy AC, Lähdesmäki H, Vlamakis H, Huttenhower C, Knip M, Xavier RJ. Genomic variation and strain-specific functional adaptation in the human gut microbiome during early life. Nat Microbiol 2019;4:470-479

86. Forbester JL, Goulding D, Vallier L, Hannan N, Hale C, Pickard D, Mukhopadhyay S, Dougan G. Interaction of Salmonella enterica serovar Typhimurium with intestinal organoids derived from human induced pluripotent stem cells. Infect Immun 2015;83:2926-2934

87. Taguchi A, Kaku Y, Ohmori T, Sharmin S, Ogawa M, Sasaki H, Nishinakamura R. Redefining the in vivo origin of metanephric nephron progenitors enables generation of complex kidney structures from pluripotent stem cells. Cell Stem Cell 2014;14:53-67

88. Mandai M, Fujii M, Hashiguchi T, Sunagawa GA, Ito SI, Sun J, Kaneko J, Sho J, Yamada C, Takahashi M. iPSC-derived retina transplants improve vision in rdl end-stage retinal-degeneration mice. Stem Cell Reports 2017;8:69-83

89. Mariani J, Coppola G, Zhang P, Abyzov A, Provini L, Tomasini L, Amenduni M, Szekely A, Palejev D, Wilson M, Gerstein M, Grigorenko EL, Chawarska K, Pelphrey KA, Howe JR, Vaccarino FM. FOXG1-dependent dysregulation of $\mathrm{GABA} /$ glutamate neuron differentiation in autism spectrum disorders. Cell 2015;162:375-390

90. Lindeboom RG, van Voorthuijsen L, Oost KC, RodríguezColman MJ, Luna-Velez MV, Furlan C, Baraille F, Jansen PW, Ribeiro A, Burgering BM, Snippert HJ, Vermeulen M. Integrative multi-omics analysis of intestinal organoid differentiation. Mol Syst Biol 2018;14:e8227 